\title{
UN NUEVO TEXTO DE TRADICIONES ESCATOLÓGICAS SOBRE AL-ANDALUS*
}

\author{
Por \\ M. ${ }^{a}$ ISABEL FIERRO y SAADIA FAGHIA
}

G. Vajda, en su artículo «Notes sur les fonds de manuscrits arabes de la bibliothèque de l'Escorial» (1), da noticia del ms. n. ${ }^{\circ} 1.063$ (Casiri, 1058). Se trata de la obra

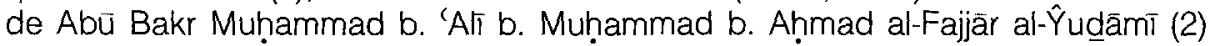
(m. 723/1323), titulada Nușh al-maqăla fi šarh al-Risāia, consistente en un comentario de la famosa Risāla de lbn Abī Zayd al-Q̇ayrawānit. El autor añade, a guisa de apéndice, un apartado dedicado a los fadā'il al-Madina (fs. 259b-260a), otro a los façā'il Mălik b. Anas (fs. 260a-261b), así como uno sobre fậä'il al-Andalus (fs. $261 \mathrm{~b}-262 \mathrm{~b}$ ), del que ofrecemos la edición (3) junto con la traducción anotada.

Las tradiciones recogidas en este apartado sobre faḍ̄'ll al-Andalus se caracterizan por su contenido escatológico. En general, no ofrecen novedades, aunque sí variantes respecto a textos ya conocidos ( $v$. las notas que siguen a la traducción). La tradición n. ${ }^{\circ} 15$ (deliciosa) no la hemos encontrado en ninguna otra fuente. El contenido del n. ${ }^{\circ} 14$ está en estrecha relación con la propaganda iniciada en época de 'Abd al-Raḥmān III, según la cual al-Andalus es una región del Islam bendecida por Dios y a salvo de toda desviación del camino recto por haberse impuesto

\footnotetext{
* Cuando este artículo ya estaba en prensa, ha aparecido el firmado por L.P. Harvey y titulado «A Morisco collection of apocryphal Hadiths ou the virtuos of al-Andalus", Al-Masāq II (1989), pp. 25-39. Las relaciones que existen entre el texto morisco y el aquí publicado serán objeto de estudio por M. ${ }^{a}$ Isabel Fierro en un próximo trabajo sobre la literatura de fạăăsil al-Andalus.

(1) AL-ANDALUS XXVIII (1963), pp. 61-94: v. pp. 86-7.

(2) Sus otras nisbas son al-ArkuŠT al-Mālaqi al-Širrıs. Se le atribuye haber escrito cerca de treinta obras, entre ellas un comentario al Mujtasar $\pi$ l-figh de al-Tulaytuti y otra sobre la prohibición de que los musulmanes vivan en tierras cristianas. V. Ibn Farhūn, al-Dibày al-mudhab (2 vois., El Cairo, s.a.), II, 288-90; GAL, I, 384; SI, 662.

(3) La escritura del manuscrito es magrebi y bastante clara.
} 
en ella la doctrina mālikí, nacida en Medina y heredera por tanto de forma directa de la sunna del Profeta (4).

La época en la que vive al-Fajjār (ss. VII-VIII/XIII-XIV) era sin duda propicia al interés por tradiciones escatológicas relativas a al-Andalus. El constante avance de los cristianos por tierras musulmanas hacía presagiar un fin más o menos próximo del lslam en la península. Con razón se dice en el n. ${ }^{\circ} 12$ que una de las excelencias de alAndalus es que haya podido perdurar como país musulmán a pesar de su proximidad con los paises cristianos. No es sin embargo al-Fajār el primero en advertir ese mérito, puesto que se limita a reproducir un pasaje de al-Humaydi (m. 488/1095). Uno de los aspectos que llaman la atención en el texto de al-Fajjär es precisamente el hecho de que se nutre de tradiciones antiguas que podrían parecer creadas ad hoc para su época. Por ejemplo, la tradición $n .{ }^{\circ} 16$ predice un avance cristiano en la península, la imposibilidad de hacerle frente por parte de los musulmanes y la huida de éstos de al-Andalus hacia lfrīiqiya. Esta predicción podría parecer una predicción post eventum, creada después de la caída de Toledo en 478/1085 y tras el comienzo de la emigración andalusí al Norte de Africa. Sin embargo, al-Fajjär no sólo toma esa tradición de una obra de Abū 'Amr al-Dānī (m. 444/1053), sino que además se trata de una tradición que estaba en circulación en Oriente hacia finales del s. II/VIII. La recoge en efecto Nu'aym b. Hammād (m. 228/844) en su Kitāa alfitan. Es, por tanto, una tradición escatológica «lograda»: la ambigüedad que caracteriza al género posibilita la lectura actualizada de este tipo de tradiciones. Al-Fajjār no deja de señalar las resonancias actuales de algunas de las tradiciones que cita, como es el caso del $n .^{\circ} 9$.

(4) V. al respecto M. ${ }^{a}$ I. FIERRO: La heterodoxia en al-Andalus durante el periodo omeya (Madrid, 1987), p. 137. 


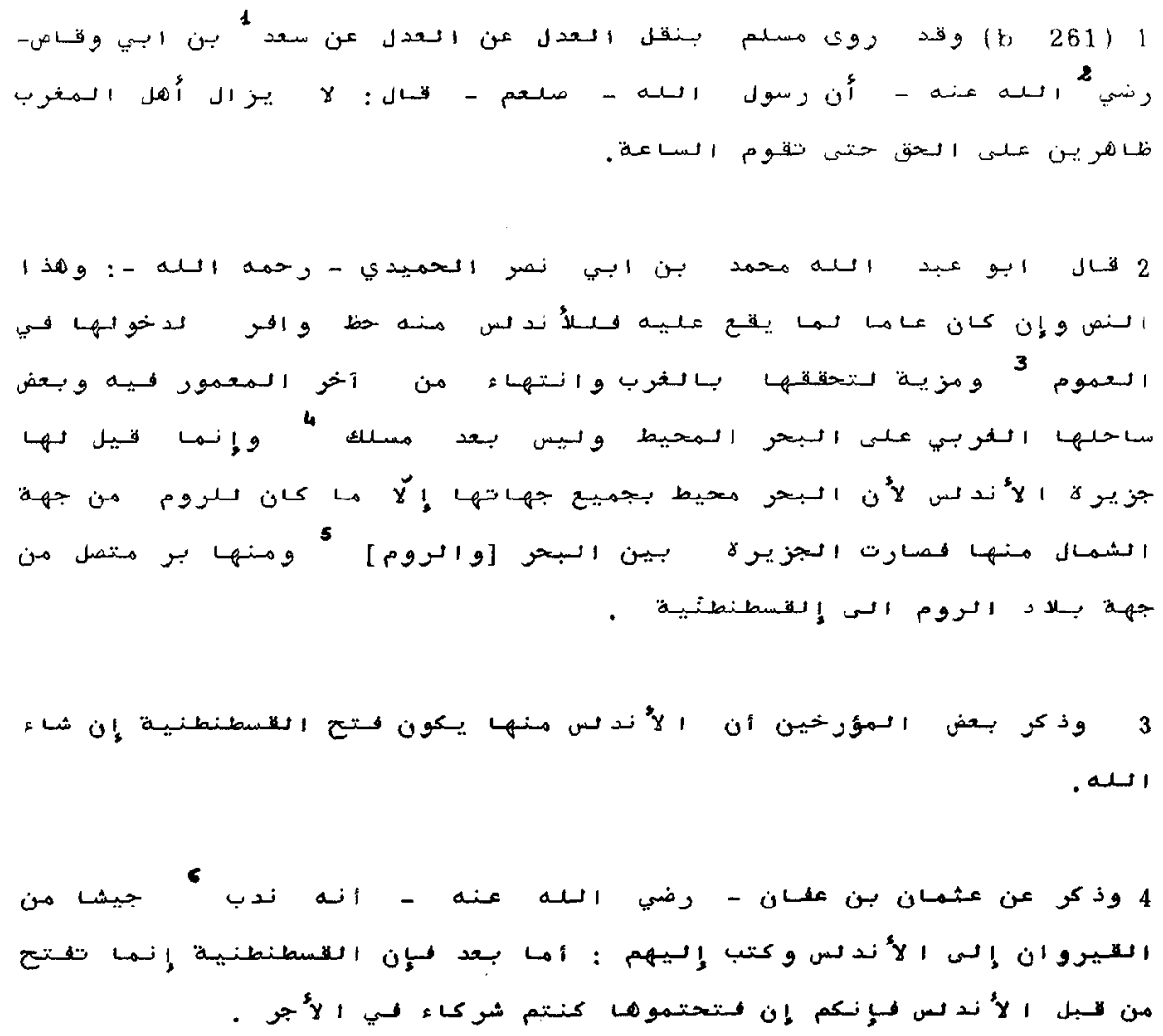




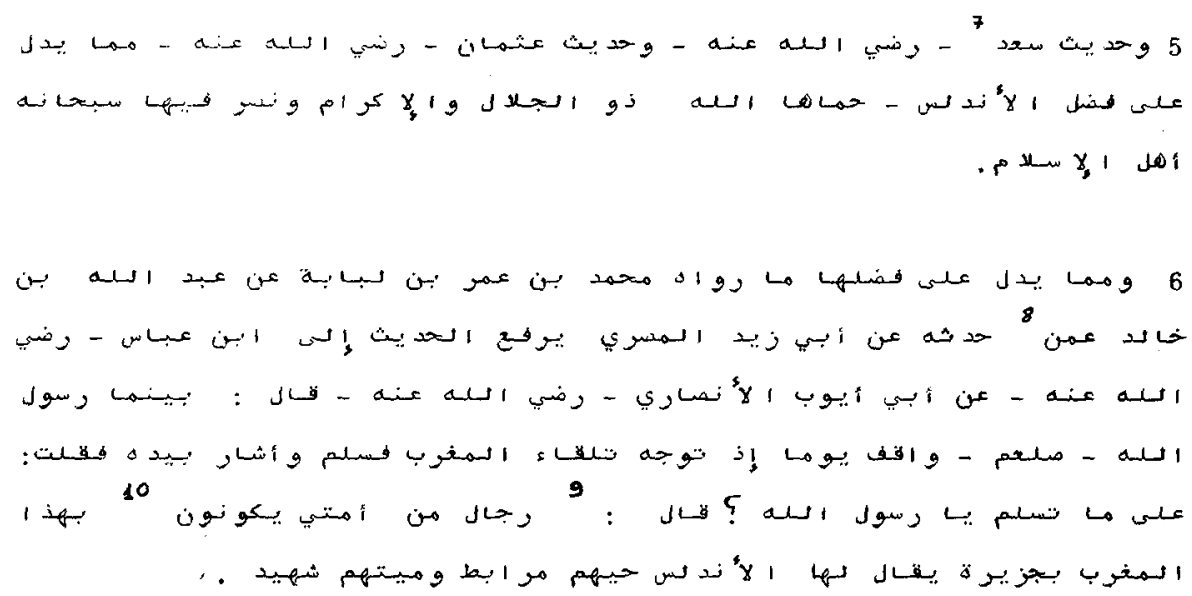


9

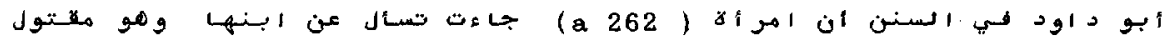

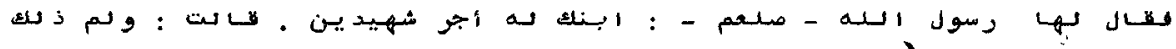

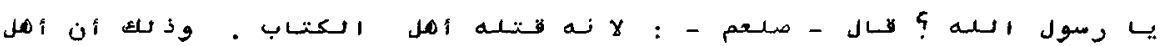

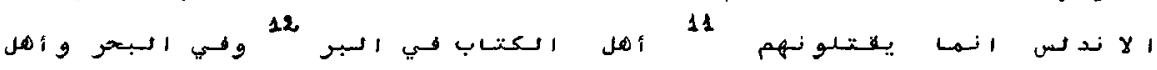

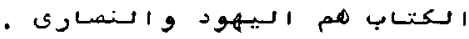

10

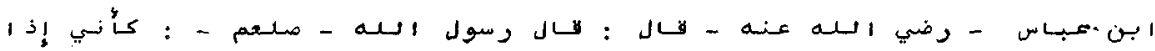

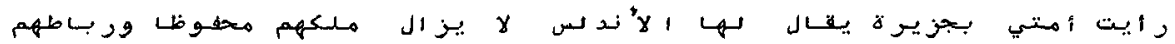

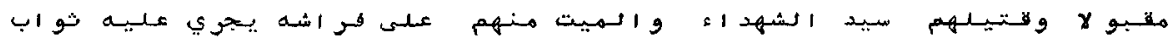

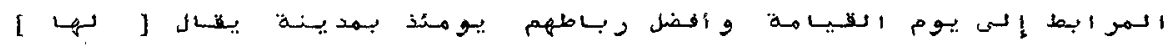

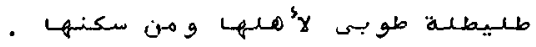

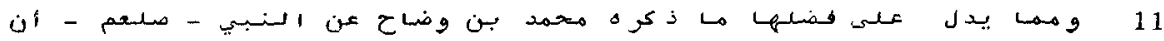

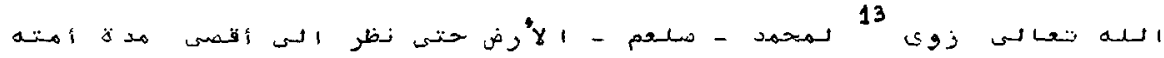

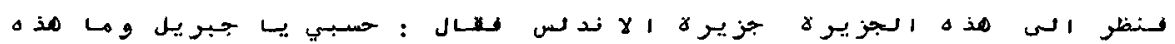
الهجزيورة

12

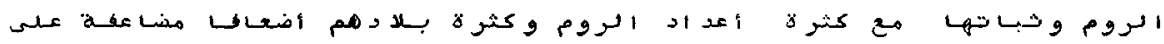

$$
\text { En el ms: } 0
$$

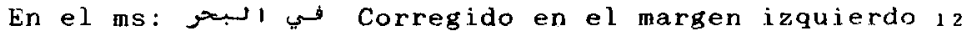

$$
\text { En el. ms: } 191 ; 13
$$

En el ms: Lث, 


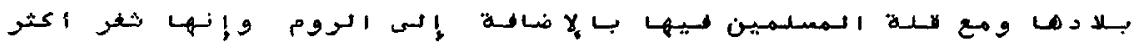
الهنغور خومسا

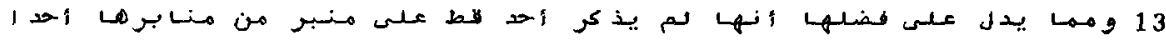

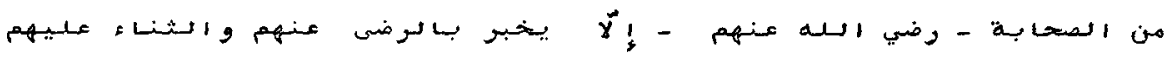
-

14

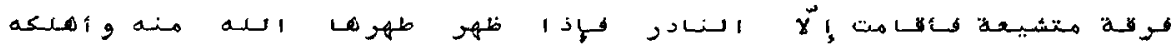

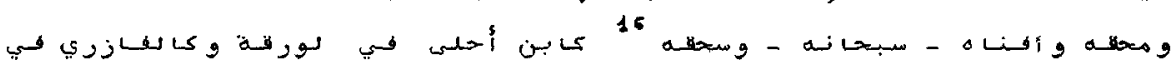

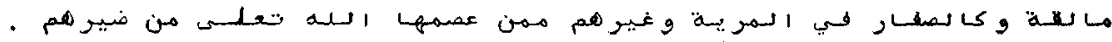
15

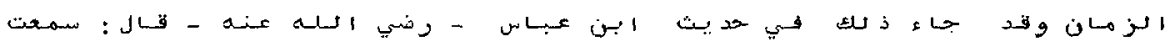

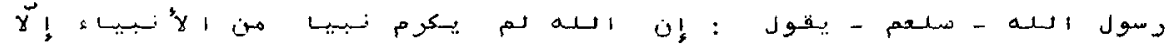

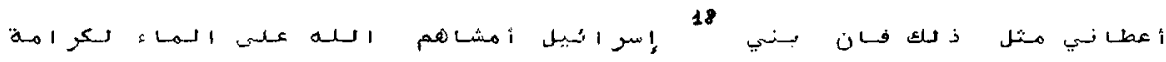

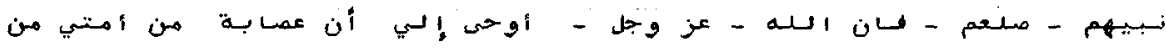

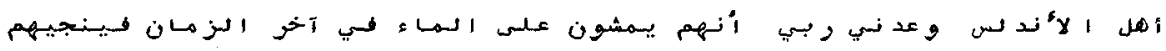

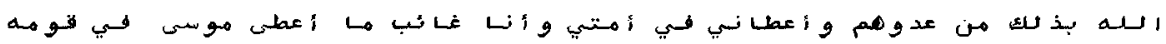

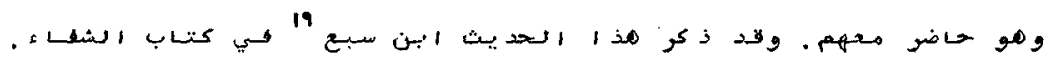

En el. ms: 15

En el ms: 16

En el ms: $\ddot{3} د$ s 17

En el ms: 2 Is

Sic en el ms. Quizás: 19 


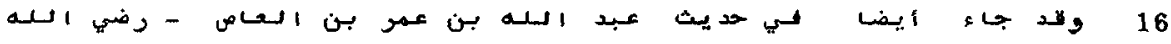

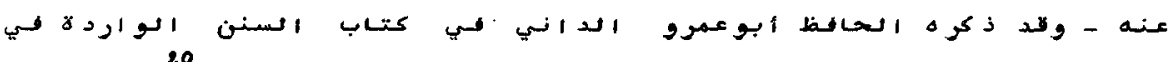

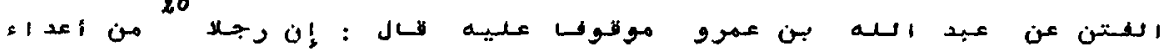

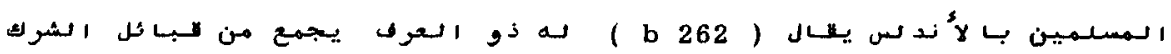

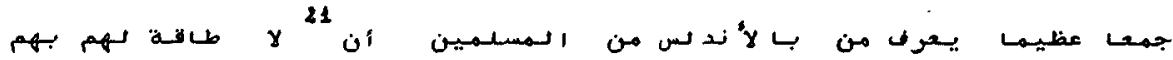

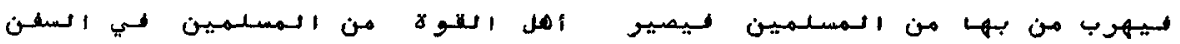

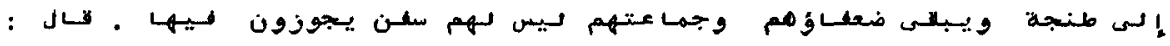

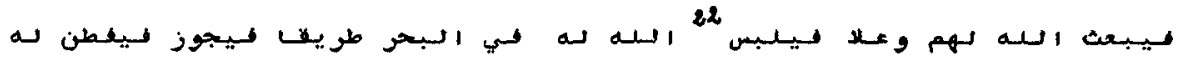

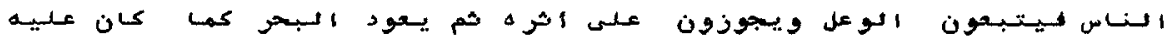

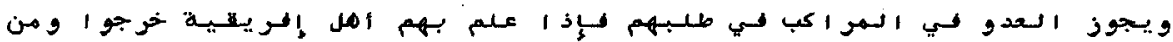

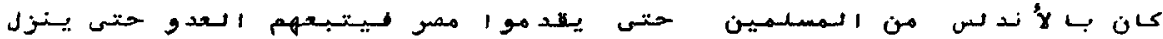

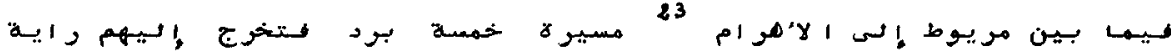

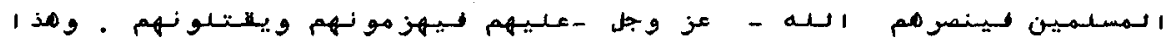

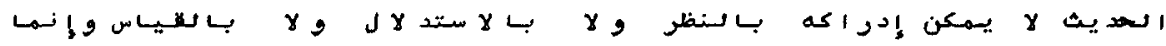

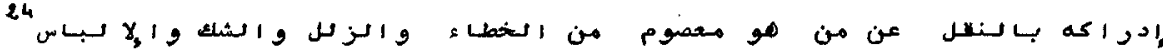

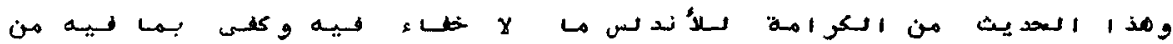

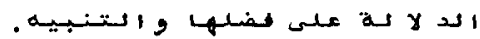

En el ms: Ja, 20

En el ms: $\hookrightarrow 21$

Sic en el ms; quizás: يسيبنص 22

Corregido según Nu 'aym b. Hammād, K. al-fitan, ed. J. Aguadé, p. 175. Sic en el ms. Quizás: 24 


\section{Traducción}

1) Transmitió Muslim, según una persona de confianza, que lo tomó de una persona de confianza que lo tomó de Sa'd b. Abi Waqqāṣ (iDios esté satisfecho de él!) que el Profeta (¡Dios lo bendiga y salve!) afirmó: "Las gentes del Magrib no dejarán de dar testimonio de la verdad hasta que llegue la Hora».

2) Dijo Abū 'Abd Allāh Muhammad b. Abī Nașr al-Humaydi (jDios tenga misericordia de él!): «Aunque este texto se puede aplicar en general a toda la zona a la que se refiere [el Occidente islámico], a al-Andalus le toca una buena parte, dado que entra en ese ámbito de aplicación general, y aún tiene ventaja, puesto que la pertenencia de al-Andalus al Occidente es indudable: por algo es la última región habitada en el oeste, cuya costa occidental está bañada por el océano sin que exista camino más allá. Se la llama «isla de al-Andalus» porque el océano la rodea por todos sus lados, excepto por el lado septentrional que está en poder de los Rūm. Es, pues, como una isla entre el mar y los Rüm. La tierra se extiende sin solución de continuidad desde el lado del país de los Rüm hasta Constantinopla».

3) Algunos historiadores han mencionado que la conquista de Constantinopla tendrá lugar a partir del al-Andalus, si Dios quiere.

4) Se ha mencionado tomándolo de 'Utmān b. 'Affān (¡Dios esté satisfecho de él!), que cuando éste envió un ejército desde Qayrawān a al-Andalus les escribió diciéndoles: «Ciertamente Constantinopla será conquistada por el lado de al-Andalus. Si vosotros la conquistáis [al-Andalus], seréis partícipes en la recompensa [de los que conquisten Constantinopla]».

5) La tradición de Sa'd [b. Abī Waqqāș] (¡Dios esté satisfecho de él!) y la tradición de 'Utmān (¡Dios esté satisfecho de él!) son pruebas de la excelencia de alAndalus. ¡Que Dios - excelso y glorioso- la proteja y que Él -alabado sea- ayude a los musulmanes!

6) Otra prueba de la excelencia de al-Andalus es lo que transmitió Muhammad b. 'Umar b. Lubāba tomándolo de 'Abd Allāh b. Jālid, quien lo tomó de otro transmisor que lo tomó de Abū Zayd al-Mișrī, remontándose el hadị hasta Ibn 'Abbās (¡Dios esté satisfecho de él!), quien lo tomó de Abū Ayyūb àl-Anșārī (¡Dios esté satisfecho de él!), quien dijo: Estando de pie un día el Enviado de Dios (iDios lo bendiga y salve!), se movió para ponerse mirando hacia Occidente, saludó e hizo señas con la mano. Le pregunté: «jOh, Enviado de Dios!, ¿a quién saludas?». Respondió: «A unos hombres de mi comunidad que estarán en ese Occidente, en una isla a la que llaman al-Andalus. El vivo de entre ellos será un defensor de la fe (murābit) y el muerto será un mártir».

7) Otra prueba de la excelencia de al-Andalus es lo que mencionó también Muhammad b. 'Umar b. Lubāba, a cuyo conocimiento había llegado que el Enviado de Dios (¡Dios lo bendiga y salve!) dijo a 'Umar b. al-Jattāb (¡Dios esté satisfecho de él!): «Tras de mi muerte se conquistará una isla a la que dicen al-Andalus: será lo último hasta donde se propague el Islam y lo primero de donde desaparezca. Constituirá el límite occidental del Islam y será una de las puertas del Paraíso. De ella vendrán a congregarse los guraba $\bar{a}^{\prime}$ de mi comunidad el día de la Resurrección. ¡Bienaventurados sean los justos de entre ellos! Serán defensores de la fe ( $m u$ - 
rābitūn) en sus propias casas y mártires en sus lechos, con la excepción de aquél cuya fe no sea la de ellos. Los mártires de otros lugares mirarán a los de alli como los seres de la Tierra miran las estrellas del cielo. Un solo día de ribät en sus fronteras será más importante que un año de ribāt en cualquier otro lugar fronterizo".

8) Otra prueba de su excelencia es el dicho del Profeta (jDios lo bendiga y salvel): "Los mejores mártires son los mártires del mar». Lo ha mencionado 'Abd alMuḥsin al-Tinnīsī en el Kitāb al-fā'iq.

9) Otra prueba de su excelencia es que aquél a quien dan muerte las gentes del Libro recibe la recompensa de dos mártires. Ha mencionado Abü Dāwūd en los Sunan que una mujer iba preguntando por su hijo que había sido muerto. El Enviado de Dios (¡Dios lo bendiga y salve!) le dijo: «Tu hijo ha recibido la recompensa de dos mártires». Preguntó la mujer: «iOh, Enviado de Dios!, ¿cómo es eso?». Contestó (Dios lo bendiga y salve!): «Porque lo mataron las gentes del Libro». Pues bien, a las gentes de al-Andalus las están matando las gentes del Libro en la tierra y en el mar. Las gentes del Libro son los judíos y los cristianos.

10) Otra prueba de la excelencia de al-Andalus es lo que mencionó Yahyà b. Ibrāhim b. Muzayn con una cadena de transmisión que se remontaba a lbn 'Abbās (¡Dios esté satisfecho de él!), quien dijo: El Enviado de Dios (¡Dios lo bendiga y salve!) afirmó: «He aquí que es como si yo viera a mi comunidad en una isla llamada al-Andalus. El poder de sus habitantes no dejará de ser conservado y su práctica del ribāt no dejará de ser aceptada. El que sea muerto de entre ellos será el señor de los mártires y el que muera en su lecho recibirá la recompensa del defensor de la fe (al-murābit) el día de la Resurrección. El ribăt más meritorio será entonces el que se haga en una ciudad llamada Toledo. ¡Bienaventuradas sean sus gentes y quienes allí se establezcan!».

11) Otra prueba de la excelencia de al-Andalus es lo que mencionó Muhammad b. Waḍ̣āh tomándolo del Profeta (jDios lo bendiga y salve!): Dios Altísimo plegó la Tierra para Munammad (jDios lo bendiga y salve!) hasta que pudo ver el término más extremo al que llegaria su comunidad. $Y$ vio esta isla, la isla de al-Andalus y dijo: «Es suficiente, joh, Ŷibrii! ¿Qué isla es ésa?». Le contestó: «Es al-Andalus. El que viva en ella, joh, Muhammad!, será un defensor de la fe (muräbit) y el que en ella muera morirá mártir».

12) Otra prueba de la excelencia de al-Andalus es su vecindad y su contigüidad con el país de los Rūm. A pesar de la abundancia del número de los Rūm, de que su pais aventaja mil veces al país de al-Andalus y a pesar del escaso número de musulmanes que en ella viven además de los Rūm, al-Andalus se mantiene. La frontera de al-Andalus es sin duda la más temida de las fronteras.

13) Otra prueba de la excelencia de al-Andalus es que nunca nadie ha mencionado desde uno de sus almimbares a ninguno de los Compañeros del Profeta (¡Dios esté satisfecho de ellos!) sin añadir la fórmula ¡Dios esté satisfecho de ellos!, sin alabarlos y $\sin$ bendecirlos.

14) Otra prueba de su excelencia es que nunca ha aparecido en al-Andalus una secta innovadora que durase, ni un grupo sectario que se mantuviese sino en muy raras ocasiones. Y cuando apareció, Dios (jalabado sea!) purificó a al-Andalus de 
ese sectario aniquilándolo, destruyéndolo, eliminándolo y aplastándolo, como hizo con Ibn Aḥlà en Lorca, con al-Fāzarì en Málaga, con al-Ṣaffār en Almería y con otros de entre aquellos de cuyo daño Dios Altísimo protegió a al-Andalus.

15) Otra prueba de la excelencia de al-Andalus es la salvación de sus gentes de los Rūm, adoradores de los crucifijos, al final de los tiempos. Se trata de este asunto en un hadit en el que Ibn 'Abbās (¡Dios esté satisfecho de él!) dice: Oí decir al Enviado de Dios: «Dios no concedió un carisma a ninguno de los profetas [anteriores a mi] sin concederme a mi el mismo carisma. Dios hizo caminar a los Banū Isrāîl sobre el agua por el carisma de su profeta. Dios me reveló y mi Señor me prometió que un grupo de mi comunidad perteneciente a la gente de al-Andalus caminarian sobre el agua al final de los tiempos y de este modo Dios los salvaría de sus enemigos. Me daría así, estando yo ausente, lo que le dió a Moisés con respecto a su pueblo estando él con ellos». Este hadit fue mencionado por Ibn Saba' en el Kitāb al-šifá'.

16) Se trata de lo mismo en el hadît de 'Abd Allāh b. 'Amr b. al-'Ass que ha mencionado el hāfiz Abū 'Amr al-Dāni en el Kitäb al-sunan al-wārida fíl-fitan remontándolo hasta 'Ábd Allāh b. 'Amr, quien dijo: «Un hombre de entre los enemigos de los musulmanes en al-Andalus, llamado $\underline{d} \bar{u}$ l-'urf, reunirá de entre las tribus del politeísmo un gran grupo. Los musulmanes que estén en al-Andalus se darán cuenta de que su fuerza no es suficiente para acabar con ellos, por lo que los musulmanes de al-Andalus se verán obligados a huir. Los fuertes de entre ellos llegarán en barcos a Tánger, permaneciendo [en al-Andalus] los débiles de entre ellos así como un grupo [de los fuertes] que no tendrá barcos para cruzar [el mar]». Añadió: "Dios les enviará un hombre eminente para el que Dios abrirá un camino en el mar por donde lo cruzará. Las gentes lo entenderán y seguirán a ese hombre, cruzando en pos de sus huellas. Luego el mar volverá a como estaba antes. Los enemigos lo cruzarán en naves en persecución de los musulmanes. Cuando las gentes de Ifrīqiya tengan conocimiento de su llegada [de los enemigos], saldrán junto con los musulmanes que estaban en al-Andalus hasta que lleguen a Egipto. Los enemigos les perseguirán hasta que hagan alto en un lugar situado entre Maryūt y al-Ahrām a una distancia de cinco burud. El estandarte de los musulmanes se les vendrá encima y Dios les concederá la victoria, pues los derrotarán y les darán muerte». Este hadit no puede ser entendido mediante argumentos racionales (al-nazar wa-l-istidläl wa-l-qiyās); su aceptación reside en el hecho de haber sido transmitido por quien está libre de error, equivocación, duda y mentira. Este hadtit relativo al carisma concedido a al-Andalus es de los que no tienen tacha. Hay en él prueba y argumento suficientes sobre la excelencia de al-Andalus.

\section{Comentario a la traducción}

1) Este hadit está recogido efectivamente en el Sahịh de Muslim, dentro del Kitäb al-imàra, con la salvedad de que en vez de ahi al-magrib aparece ahl al-garb. Esta expresión ha sido interpretada de diversas formas y no siempre en relación con la zona occidental del Islam: v. el comentario de al-Nawawî a la obra de Muslim ( 18 vols. en 6, El Cairo, s.a., XIII, 68). La lectura al-magrib aparece en la Yad'wat almuqtabis de al-Humaydī (ed. M. b. Tāwit al-Tanŷi, El Cairo, 1952, p. 7). La fuente 
(no se si primaria o secundaria) de al-Fajjār es sin duda el texto de al-Humaydi, a quien cita expresamente a continuación ( $v . n{ }^{\circ} 2$ ).

Para otras referencias a obras en las que se recoge el mismo hadit, v. Dikr bilād al-Andalus (ed. y trad. L. Molina, 2 vols., Madrid, 1983), 10/12, n. ${ }^{\circ} 14$ y II, 239, así como J. Vallvé, La división territorial de la España musulmana (Madrid, 1986), pp. 29-30.

2) Este texto, como ya hemos indicado, está recogido en la Ŷadwa de al-Humaydi, si bien la cita no es literal, faltando un pasaje que corresponde al $n .{ }^{\circ}$ i3. Al-Humaydi es citado también por al-Dabbī, Bugyat al-multamis, pp. 10-1 (ed. El Cairo, 1967); Ibn Iḍārī, al-Bayān al-mügrib, I, 7 (ed. G.S. Colin y E. Lévi-Provençal, 2 vols., Leiden, 1948-51); Dikr, 10/22, n. ${ }^{\circ} 15$.

3) El primer historiador en hacer tal afirmación parece haber sido Sayf b. 'Umar (m. 193/809) (GAS, l, 311-2): v. las referencias que damos a continuación en el $n .{ }^{\circ} 4$.

4) Un texto prácticamente igual está recogido por al-Maqqarī, Nafh al-tib, I, 204 (8 vols., Beirut, 1398/1968). Alli se especifica que su transmisor fue Sayf b. Ümar. La fuente de al-Maqqarī parece ser una obra de lbn Baškuwäl consistente en alahādit wa-l-ätār fi sa'n fadl al-Andalus wa-l-Magrib. Según al-Maqqari, esas tradiciones fueron reproducidas por Ibn Sa'ìd en su Kitāb al-mugrib, pero no lo encontramos en la edición de S. Dayf (2 vols., El Cairo, 1964). Aprovechamos para señalar que al-Maqqari recoge el texto en cuestión acompañándolo de comentarios en los que muestra la poca credibilidad que le merece.

Una versión más amplia de la transmisión de Sayf b. 'Umar está recogida por alTabarī en su Ta'rīj al-rusul wa-l-mulük, así como por lbn al-Atîr en al-Kāmil fi l-ta'rij]: v. al respecto Vallvé, ob. cit., pp. 31-2. Otras variantes en al-Bakrī, Kitāb al-masālik (ed. parcial de 'Abd al-Rahmān 'A Rawd al-mițär (ed. y trad. Ė. Lévi-Provençal, Leiden, 1938, p. 3/6); Dikr, 16-27, n. ${ }^{\circ}$ 32; à-Qurtubi, al-Tadkira fi ahwäl al-mawtà wa-umür al-äjira (2 vols. en 1, Beirut, 1406/1986), II, 353.

5) Las expresiones finales casan bien con la difícil situación de los musulmanes en al-Andalus en tiempos de al-Fajjār.

6) El mismo texto está recogido por Ibn 'I dāañ en Bayān, I, 7: v. la traducción de Vallvé, ob. cit, pp. 23-4.

Numerosas variantes de esta tradición se encuentran en Dikr, 11-12/23, n. ${ }^{\circ} 18$; 12-13/24, n. ${ }^{\circ} 24$; textos relacionados pueden verse en la misma obra (11-15/22-26).

Ibn Lubāba (m. 314/926) y 'Abd Allāh b. Jālid (m. 261/874) son ulemas andalusies (v. M. Marín, «Nómina de sabios de al-Andalus», Estudios onomástico-biográficos de al-Andalus. I, Madrid, 1988, pp. 24-182, $n .^{\circ} 1.283$ y 810). Otros andalusíes que tuvieron parte en la transmisión de este tipo de tradiciones, de acuerdo con la información suministrada por el Dikr, fueron: 'Abd al-Malik b. Habib (m. 238/852), Yahyà b. Yahyà (m. 234/848, de quien transmite Muhammad b. Waḍdāh, m. 287/900), Baqi b. Majlad (m. 276/889), Muhammad b. Yüsưf b. Mațrūh (m. 271/884), Abū Umar b. 'Abd al-Barr (m. 463/1071), Ibn al-Tallā' (m. 497/1099).

7) El mismo texto, con alguna variante, en Dikr, 13/24, n. ${ }^{\circ} 24$. Para el concep- 
to de gurabā', v. al-Ṭurțūšì, Kitāb al-ḥawādit wa-l-bida' (ed. M. Talbi, Túnez, 1959), p. 25.

8) Para el autor mencionado v. GAL, SII, 931. Sobre los méritos atribuidos a los musulmanes que mueren combatiendo en el mar, v. M. Amari, Storia dei musulmani di Sicilia, vol. I (Florencia, 1854), p. 81. wūd.

9) Este hadit está recogido en el Kitāb al-yihāa (n. ${ }^{\circ}$ 8) de la obra de Abū Dā-

10) El transmisor de esta tradición, Yahyà b. Ibrāhīm b. Muzayn (m. 259/872 o 266/879), es un ulema originario de Toledo y establecido en Córdoba ( $v$. Marin, art. cit., $n{ }^{\circ}$ 1.523). La última parte de la tradición parece un añadido hecho en Toledo por ulemas toledanos (tal vez por el propio Ibn Muzayn) a un hadit que estaba en circulación en al-Andalus desde la época de 'Abd al-Malik b. Habīb.

11) Una variante, más extensa, está recogida en Dikr, 13-14/25, n. ${ }^{\circ} 26$ (el editor, L. Molina, remite a otras variantes recogidas por Ibn al-Šabbāt, Ibn Simāk y alMaqqarī). El isnād en este caso es el siguiente: Ibn Waḍ̂ạh _ـ Yahyà b. Yahyà al-Layț —_ Mālik b. Anas.

12) Este pasaje está tomado de la Yadwa, pp. 7-8, si bien no se trata de una cita literal; los cambios introducidos no mejoran el texto. Otros autores que se inspiran en al-Humaydi son al-Dabbī y el anónimo autor del Dikr, 15/26, n. ${ }^{\circ} 30$.

13) Nuevamente se trata de una idea tomada de al-Humaydi sin ser cita literal, ya que el texto de la $\hat{Y} a \underline{d} w a(p .7)$ reza simplemente: «En sus almimbares nunca se ha mencionado a ningún miembro de las primeras generaciones del Islam (al-salaf) sino era para bien». V. también Dikr, 15/16, n. ${ }^{\circ} 30$.

Recuérdese que se atribuye a Umar b. Hafșun haber prestado obediencia al ši ' ' Ubayd Allāh, quien le habría escrito indicándolo «su manera de hacer la llamada la oración, los rezos y el sermón y le ordenaba que estableciera esos métodos en al-Andalus". No parece probable que lbn Hafșun adoptara esos métodos, que incluian la descalificación de los primeros califas: $v$. Fierro, Heterodoxia, pp. 122-3.

14) De los tres herejes mencionados hemos podido identificar al primero y al segundo. El primero es Muhammad b. 'Ali b. Ahlà al-Mubtadi': v. Ibn al-Zubayr, Silat al-Sila, ed. E. Lévi-Provençal (Rabat, 1937), p. 140. El segundo es el falso profeta y șüfí malagueño Ibrāhìm al-Fazāñ, protegido de los Banū Ašqiilūla: v. M. ${ }^{a} \mathrm{~J}$. Rubiera, «Los Banū Escallola, una dinastía granadina que no fue», Andalucia Islámica, II-III (1981-2), pp. 85-94.

15) No hemos podido localizar a la fuente de al-Fajjār. Sobre la conquista de al-Andalus al final de los tiempos, v. Dikr, 14-15/25-6, n. 29.

16) Se trata de una variante de un hadit más extenso recogido en el Kitāb alfitan de Nu'aym b. Hammād (m. 228/844): v. la edición realizada por J. Aguadé en su artículo «Algunos hadices sobre la ocupación de Alejandria por un grupo de hispano-musulmanes» (BAEO XII (1976), pp. 159-180), pp. 174-5, donde señala obras orientales posteriores que incluyen la misma tradición. Sobre la fechación de este hadit, v. también M. Cook, «Eschatology, history and the dating of traditions», co- 
municación leída en el Third International Colloquium «From Jahiliyya to Islam», 30 junio - 7 julio 1985 (en prensa).

Sobre los diferentes significados del término wal, v. Lisān al-arab, s.v.

La obra de Abū 'Amr al-Dānī con el título de Kitäb fi l-fitan wa-l-ašrät es mencionada por Ibn al-Abbär, al-Takmila, ed. '. al-'Attār al-Husaynī (2 vols., El Cairo, 1375/1955), n. ${ }^{\circ} 810$. 